\title{
Positive and negative likelihood ratios of two anthropometric indices (Waist/Height Index and Waist/Hip Index) in the diagnosis of pathological nutritional situations overweight and obesity
}

DOI: $10.46932 / \mathrm{sfjdv2n2-016}$

Received in: january 1st, 2020

Accepted in: March 30th, 2020

\author{
José Franco-Monsreal \\ Doctor en Ciencias Médicas \\ E-mail: jose.franco@uimqroo.edu.mx \\ Alicia May-Panti \\ Licenciada en Salud Comunitaria \\ E-mail: alicia.may@uimqroo.edu.mx
}

\author{
Lidia Esther del Socorro Serralta-Peraza \\ Maestra en Educación \\ E-mail: lidia.serralta@uimqroo.edu.mx; \\ María Selene Sánchez-Uluac \\ Maestra en Ciencias \\ E-mail: selene.sanchez@uimqroo.edu.mx
}

\begin{abstract}
Background and objective. Koch et al., reported that the Waist/Hip Index more accurately predicts cardiovascular risk factors and mortality. Huaman et al., reported that the Waist/Height Index can be used as a diagnostic test for metabolic syndrome, since it has a high significant value. To determine whether two anthropometric indices have sufficient prognostic efficiency or moderate prognostic efficiency by combining sensitivity and specificity using positive and negative likelihood ratios in a single expression. Material and methods. Quantitative epistemological approach. Descriptive observational epidemiological study without directionality and with prospective temporality. Three husband adult patients of both genders who attended the Integral Hospital "Jose Maria Morelos" were studied. As a reference test or Gold Standard was used the Lorentz Equation as a reference test. Results. The results for the positive likelihood ratios corresponded to 13.41 and 1.72 for the anthropometric indices Waist/Height Index and Waist/Hip Index, respectively. The results for the negative likelihood ratios corresponded, respectively, to 0.07 and 0.48 for the anthropometric indices Waist/Height Index and Waist/Hip Index. Conclusions. The best anthropometric index for the diagnosis of overweight and obesity pathological nutritional situations corresponds to the Waist/Height Index, since the results of the positive and negative likelihood ratios report sufficient prognostic efficiencies. On the other hand, the results of the positive and negative likelihood ratios report, respectively, negligible prognostic efficiency and poor prognostic efficiency for the Waist/Hip Index.
\end{abstract}

Keywords. Likelihood ratios, anthropometric indices. 


\section{INTRODUCTION}

The pathological nutritional situations overweight and obesity are risk factors for numerous chronic diseases. The increase in its incidence and prevalence worldwide has become a serious and growing public health problem that reaches alarming proportions in some countries ${ }^{(\mathbf{1})}$.

In the present study the Lorentz equation was used as a reference test which provides the ideal body weight $(\mathrm{IBW})^{(2)}$.

Koch et al., in a sample of 13,054 adults [6,714 (51.43\%) men and 6,340 (48.57\%) women] aged 20-90 years, reported the relationship between anthropometric indices of adiposity, cardiovascular risk factors and mortality. The anthropometric indices of adiposity were the Body Mass Index (BMI), the abdominal circumference (AC), the Waist/Hip Index and the Waist/Height Index which are known to be associated with risk factors metabolic. The authors evaluated the performance of each index to detect arterial hypertension, type 2 diabetes mellitus, and dyslipidemias. In both genders, BMI did not show an independent effect on mortality after controlling for age and other risk factors. Compared with other anthropometric indices proposed in the literature, the Waist/Height Index presented the best sensitivityspecificity relationship to predict a mortality outcome. Finally, the authors conclude that the Waist/Height Index makes it possible to predict cardiovascular risk factors and mortality with greater precision ${ }^{(3)}$.

Huaman et al., in a population aged 20-79 years, report the inclusion of 610 adults [299 (49.02\%) men and 311 (50.98\%) women] residents of the Trujillo district. The authors concluded that Waist/Height Index can be used as a diagnostic test for metabolic syndrome since it has a high significant value ${ }^{(4)}$

It is important to emphasize that the properties of a diagnostic test that allow us to quantify the magnitude and direction of the change from prior probability or prevalence to posterior probabilities are the positive and negative likelihood ratios. In practice, if the prior probability or prevalence of a particular disease or event of interest is known or can be determined and the reasons for positive and negative likelihood of the diagnostic test are known, the "Fagan Nomogram" can be used to determine the posterior probabilities. In the Fagan Nomogram, the left column represents the prior probability or prevalence, the middle column represents the positive and negative likelihood ratios, and the right column represents the posterior probabilities. By drawing a straight line, with a ruler, the first two values are joined, and the posterior probabilities can thus be determined. In the Fagan Nomogram, the most significant changes in the probability of disease or event of interest occur with diagnostic tests that have positive likelihood ratio values $>10.00$ or negative likelihood values $<0.10$, which are usually especially useful to confirm or rule out the specific disease or event of interest.

The Fagan Nomogram is a useful tool for calculating posterior probabilities once the prior probability or prevalence and the positive and negative likelihood ratios are known. The prior probability 
is usually known and is nothing more than the prevalence of the disease to be diagnosed in the group from which the patient comes. The likelihood ratio is calculated as the Sensitivity/(1-Specificity) ratio. Thus, the posterior probability can be obtained, which will determine the need for more diagnostic tests or the start of treatment in case of positive results, or it allows us to reasonably rule out the disease in case of negative test results ${ }^{(5)}$.

The objectives of the present study were: 1 . To determine whether each of the Waist/Height Index and Waist/Hip Index anthropometric indices has sufficient prognostic efficiency or moderate prognostic efficiency by combining sensitivity and specificity in a single expression using the ratios of positive (RV+) and negative ( $\mathrm{RV}_{-}$) likelihood; and 2. Determine if the sensitivity, specificity, and safety of the Waist/Height Index are different from the sensitivity, specificity, and safety of the Waist/Hip Index.

Null hypothesis $\left(\mathrm{H}_{0}\right)$. There is no statistically significant evidence at the significance level $(\alpha)$ of $5 \%$ to conclude that the sensitivity, specificity and safety of the Waist/Height Index are different from the sensitivity, specificity and safety of the Waist/Hip Index: $\mathrm{x}^{2} \mathrm{P}(\alpha=0.0500 ; \mathrm{gl}=1)<3.8416 ; p>0.0500$.

Alternative hypothesis $\left(\mathrm{H}_{1}\right)$. There is statistically significant evidence at the significance level $(\alpha)$ of $5 \%$ to conclude that the sensitivity, specificity and safety of the Waist/Height Index are different from the sensitivity, specificity and safety of the Waist/Hip Index: $\mathrm{x}^{2} \mathrm{P}(\alpha=0.0500 ; \mathrm{df}=1) \geq 3.8416 ; p \leq 0.0500$.

Null hypothesis $\left(\mathrm{H}_{0}\right)$. The positive and negative likelihood ratios of the Waist/Height Index and Waist/Hip Index anthropometric indices are equal.

Alternative hypothesis $\left(\mathrm{H}_{1}\right)$. The positive and negative likelihood ratios of the Waist/Height Index and Waist/Hip Index anthropometric indices are different.

\section{MATERIAL AND METHODS}

\subsection{EPISTEMOLOGICAL APPROACH}

Quantitative approach, probabilistic approach or positivist approach ${ }^{(6)}$.

\subsection{STUDY DESIGN}

Descriptive observational epidemiological study with no directionality and prospective temporality ${ }^{(7)}$.

\subsection{STUDY UNIVERSE}

The study was carried out in 300 patients [119 (39.67\%) of the male gender and $181(60.33 \%)$ of the female gender] aged 18-64 years who attended the Hospital Integral "Jose Maria Morelos" of the 


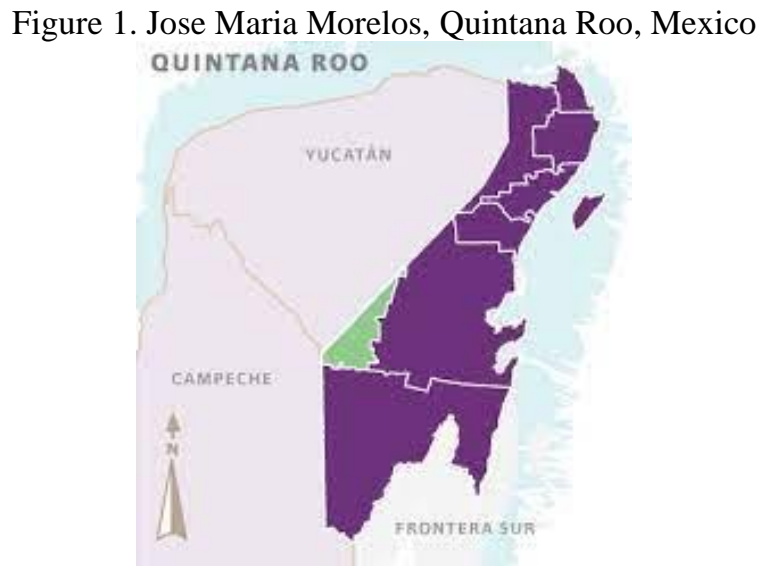

- Geographic location. The municipality of Jose Maria Morelos is in the western center of the Mexican state of Quintana Roo. It has an area of $6,739 \mathrm{~km}^{2}$, which represents $13.2 \%$ of the state surface and occupies the third place in territorial extension. It is located within the geographic coordinates of $20^{\circ} 19^{\prime}$ north latitude and $89^{\circ} 19^{\prime}$ west longitude ${ }^{(8)}$.

-Population. The Mayan municipality of Jose Maria Morelos is in the Mexican state of Quintana Roo and according to the last Encuesta Intercensal carried out in 2015 it has a population of 37,502 inhabitants of which 19,194 (51.18\%) are men and 18,308 (48.82\%) are women. Jose Maria Morelos is a developing municipality for which it has various institutions which are for the support of the locality, such as, for example, the Integral Hospital "Jose Maria Morelos" and the dining room for the elderly. It also has a multiple care center; two initials; seven preschoolers; a full-time Primary; three primaries of morning and evening shifts; a double shift high school; a double shift high school; and the Universidad Intercultural Maya de Quintana Roo which, likewise, is a double shift ${ }^{(8)}$.

-Weather. The climate is warm-sub-humid with rains in summer, with an average annual rainfall of $1,268 \mathrm{~mm}$ and an average annual temperature of $25.9^{\circ} \mathrm{C}$. The warm-sub-humid climate favors the cultivation of sugar cane; jalapeno pepper; corn; rice; vegetables and fruit trees such as sapodilla; orange; pink grapefruit; papaya; bitter lemon; mango; and pineapple; among other ${ }^{(\mathbf{8})}$.

- Hydrography. It does not have coastlines or surface water currents, but there are two main lagoons: the Chichankanab and Esmeralda lagoons. It also has cenotes and aguadas in some communities (8).

- Services. The services that the municipality has are basic services such as electricity; drinking water; and excused. Only in the last Encuesta Intercensal 2015 carried out 96\% of the population has electricity and the rest of the solar systems. About water service, not all families have it, since some 
families obtain well water, from the collection of rainwater and drinking water. Finally, the surveys carried out in the Encuesta Intercensal 2015 showed that $82 \%$ of the population has drainage ${ }^{(8)}$.

-Streets. It has streets, but these are in poor condition. It can be said that $90 \%$ of the municipality has paved streets ${ }^{(8)}$.

- Parks. It has a main park in good condition where children go out to play and adults to talk. Similarly, it has a sports unit; 18 basketball courts; 2 baseball fields; 3 fast soccer fields; 8 multipurpose fields; and 2 soccer fields ${ }^{(8)}$.

-Flora. The medium sub-evergreen forest predominates, from which woods such as mahogany (Swietenia macrophylla) are extracted; the sapodilla (Manilkara zapota); the chacté (Tecoma stans); the ramón (Brosimun alicastrum); the tzalán (Lysiloma latisiliquum); the guaya (Melicoccus bijugatus); the balché (Lonchocarpus longistylus); and cedar (Cedrus). It is important to mention that the municipality has important timber forest resources calculated in more than $52,000 \mathrm{~m}^{3}$ of precious woods and around $32,000 \mathrm{~m}^{3}$ of tropical type ${ }^{(8)}$.

-Fauna. There are important animals for their ecological, economic and tourist values such as the deer (Cervidae); the jaguar (Panthera onca); the opossum (Didelphimorphia); the armadillo (Dasypodidae); the ocelot (Leopardus pardalis); the otter (Lutrinae); the spider monkey (Ateles); the howler monkey (Alouatta palliata); the tapir (Tapirus); the wild boar (Sus scrofa); the fox (Vulpes); and the badger (Meles meles). Reptiles such as the boa (Boa); the coral (Lampropeltis); turtles (Testudine); and iguanas (Iguanidae). Among the typical birds of the area are the toucan (Ramphastidae); the macaws (Ara); parakeets (Psittacara holochlorus); the woodpecker (Picidae); the pheasant (Phasianus colchicus); the chachalacas (Ortalis); herons (Ardeidae); the cenzontle (Mimus polyglottos); hummingbirds (Trochilidae); and the hawks (Falco) ${ }^{(\mathbf{8})}$.

- Scholarship. In 2010, 86.8\% of children between the ages of 3 and 5 attend School, while in 2015 the results were that $98 \%$ attend School. Therefore, making a comparison on illiteracy only in 2000, $7.5 \%$ of 15 -year-olds could not read or write, but this indicator was reduced to $3.9 \%$ in 2015 . Regarding the level of education of the inhabitants, the Encuesta Intercensal because of $2015,7.5 \%$ of people barely finished high school ${ }^{(8)}$.

- Job. Until 2017, 59\% of the population is economically active, the rest are engaged in noneconomic activities (household chores, students, retirees and pensioners), with women being characterized by non-economically active activities, while men predominate in the economically active population ${ }^{(8)}$.

-Living place. In 2015, most of the homes had 2 and 3 rooms, 35.5\% respectively. Therefore, the houses with 1 or 2 bedrooms were $56.2 \%$ respectively. Only $4.42 \%$ of the total homes had Internet 
access (415 homes); $79.3 \%$ owned at least one television (7,455 homes); $11.72 \%$ claimed to have a computer (1,100 homes); and 57.1\% acquired at least one mobile phone (5,364 homes) ${ }^{(8)}$.

- Fertility rate. The last Encuesta Intercensal carried out in 2015 showed that women have two and more children between the ages of 15 and $49^{(8)}$.

-Mortality rate. Similarly, it stands out among populations with more than $6 \%$ of deceased children ${ }^{(8)}$.

- Health. It has an Integral Hospital, a Clinic of the Mexican Institute of Social Security and a Health Institute of Social Security for State Workers, as well as private institutions. 90\% are affiliated with Seguro Popular and the rest in other institutions. It is worth mentioning that in the municipality, SESA coordinates 31 health homes and 32 health technicians. The health care options most used in 2015 were the SSA Health Center or Hospital (Seguro Popular); consulting room; private clinic or hospital; and ISSSTE. In the same year, the social insurances that grouped the largest number of people were Seguro Popular or for a New Generation (XXI century) and they do not receive medical attention. In 2015, 52.4\% of the population was in a situation of moderate poverty and $27.1 \%$ in a situation of extreme poverty. The vulnerable population due to social deprivation reached $14 \%$, while the vulnerable population due to income was $2.32 \%$. It is important to mention that Jose Maria Morelos has the "Doctor at Home" service, since with this program he approaches and provides more and better opportunities to access health services to people with physical, economic or demographic difficulties to go to a health unit. During these days consultations are offered; application of diabetes mellitus tests; obesity; arterial hypertension; prostatic hyperplasia; breast exams; and cytologies for the prevention of cervical cancer. Nutrition talks are also given; prevention of family and gender violence; Family planning; and use of contraceptive methods, among others ${ }^{(8)}$.

\subsection{OPERATIONAL DEFINITIONS OF THE VARIABLES}

—Likelihood ratios (RV). Likelihood ratios (LR) are a valuable procedure for evaluating a diagnostic test. Likelihood ratios, also called likelihood ratios (LR) or prognostic efficiency indices (IEP), combine sensitivity and specificity in a single expression ${ }^{(9)}$.

- $\mathbf{R V}+$. The RV+ is the ratio obtained between true positives (Sensitivity) and false positives (1 - E). The RV+ responds to the following formula: Sensitivity/(1-E) ${ }^{(\mathbf{1 0})}$. An RV+> 1 indicates that there is a high probability that the patient has the disease and the higher the value obtained, the greater the probability of having the disease ${ }^{(11)}$. 
- $\mathbf{R V}$-. The RV- is the quotient obtained between the false negatives (1-Sensitivity) and the true negatives (E). An RV $-<1$ decreases the probability that the patient has the disease or event of interest (12).

-Waist/Height Index. The Waist/Height Index is defined as the quotient between waist circumference and height, both measured in the same units. The Waist/Height Index is a measure of the distribution of body fat. Higher Waist/Height Index values indicate a higher risk of obesity related to cardiovascular diseases correlated with abdominal obesity more precisely than BMI (13).

-Waist/Hip Index. The World Health Organization establishes normal values for the Waist/Hip Index $\leq 1.00$ units and $\leq 0.80$ units for the male and female genders, respectively. Higher values indicate abdominovisceral obesity, which is associated with an increased cardiovascular risk and an increase in the probability of acquiring diseases such as hypertensive vasculopathy and type 2 diabetes mellitus. The Waist/Hip Index is the quotient obtained by dividing the waist circumference by height of the last floating rib between the maximum perimeter of the hip at the level of the buttocks ${ }^{(14-15)}$.

\subsection{TECHNIQUES AND PROCEDURES}

The data were collected in the Clinical Archives Department of the Integral Hospital "Jose Maria Morelos" in the Mayan municipality of Jose Maria Morelos, Quintana Roo, Mexico. The Integral Hospital "Jose Maria Morelos" belongs to the Sanitary Jurisdiction No. 3 of the Mexican state of Quintana Roo.

\subsection{DATA PROCESSING}

In the elaboration stage the data were reviewed; classified; computerized; presented; and summarized. In the analysis and interpretation stages the data were analyzed and interpreted, respectively. $2 \times 2$ contingency tables were constructed from which the Sensitivity, Specificity, Security, RV(+) and $\mathrm{RV}(-)$ and the estimation intervals at the $95 \%$ confidence level (CI 95\%) were calculated. for RV(+) and $\mathrm{RV}(-)$ for each of the two diagnostic tests. Pearson's Chi-Square statistic $\left(\mathrm{x}^{2} \mathrm{P}\right)$ was used as a hypothesis test. The Epi lnfo software for Windows, Version 7.1.5.2, was used to obtain the values of both the $\mathrm{x}^{2} \mathrm{P}$ statistic and the probabilities $(p)$. The criterion applied in carrying out the hypothesis tests for the difference between two percentages was based on the following recommendations: 1 . When $\mathrm{N}>40$ use the $\mathrm{x}^{2} \mathrm{P}$ test; 2 . When $20 \leq \mathrm{N} \leq 40$ use the $\mathrm{x}^{2}$ P test if, and only if, all expected frequencies are $\geq 5$; if in any cell there is at least one expected frequency $<5$ then use Fisher's exact probability test (PPEF); and 3. When $\mathrm{N}<20$ use the PPEF ${ }^{(16)}$. As a reference test, the Lorentz equation ${ }^{(2)}$ was used.

$$
\mathrm{X}^{2} \mathrm{P}=\sum(|\mathrm{O}-\mathrm{E}|-0.48)^{2} / \mathrm{E}
$$




$$
\mathrm{PPEF}=(\mathrm{A}+\mathrm{B}) !(\mathrm{C}+\mathrm{D}) !(\mathrm{A}+\mathrm{C}) !(\mathrm{B}+\mathrm{D}) ! / \mathrm{N} ! \mathrm{A} ! \mathrm{B} ! \mathrm{C} ! \mathrm{D} !
$$

IBW in Men= Height (in cm) $-100-[($ Height (in cm $)-150) / 4]+[$ Age -20$) / 4]$

IBW in Women= Height $($ in cm $)-100-[($ Height $($ in $\mathrm{cm})-150) / 4]+[$ Age -20$) / 2.5]$

\subsection{RESULTS}

According to the reference test, $171(57.00 \%)$ patients with overweight and obesity and 129 (43.00\%) patients without overweight and obesity were labeled. Of the 171 patients labeled as overweight and obese, $56(32.75 \%)$ and $115(67.25 \%)$ were male and female, respectively. On the other hand, of the 129 patients without overweight and obesity, $106(82.17 \%)$ and $23(17.83 \%)$ patients corresponded, respectively, to the male and female genders.

Table 1 shows the $\mathrm{RV}(+)$ and $\mathrm{RV}(-)$ according to the capacity of the diagnostic test.

Table 1. Prognostic efficiency indices or positive and negative likelihood ratios according to the capacity of the diagnostic test.

\begin{tabular}{|l|l|}
\hline $\begin{array}{l}\text { Prognostic Efficiency Indices (IEP) or } \\
\text { positive and negative likelihood ratios }\end{array}$ & Diagnostic test capacity \\
\hline $\mathrm{RV}(+) \geq 10.00$ & Enough \\
\hline $\mathrm{RV}(+) \geq 5.00$ & Moderate \\
\hline $\mathrm{RV}(+) \geq 2.00$ & Limited \\
\hline $\mathrm{RV}(+) \geq 1.00$ & Insignificant \\
\hline & \\
\hline $\mathrm{RV}(-) \leq 0.70$ & Enough \\
\hline $\mathrm{RV}(-) \leq 0.20$ & Moderate \\
\hline $\mathrm{RV}(-) \leq 0.48$ & Limited \\
\hline $\mathrm{RV}(-)<1.00$ & Insignificant \\
\hline & \\
\hline $\mathrm{RV}(-)>0.70$ & Moderate \\
\hline $\mathrm{RV}(-)>0.20$ & Limited \\
\hline $\mathrm{RV}(-)>0.48$ & Insignificant \\
\hline
\end{tabular}

The absolute frequencies of the 300 patients for positivity (Waist/Height Index $>0.5$ units) and for negativity (Waist/Height Index $\leq 0.5$ units) according to the Waist/Height Index diagnostic test and for pathological nutritional situations overweight and obesity according to the reference test are presented in Table 2. 
Table 2. Absolute frequencies of the 300 patients due to positivity (Waist/Height Index > 0.5 units) and negativity (Waist/Height Index $\leq 0.5$ units) according to the Waist/Height Index diagnostic test (in units) and due to pathological nutritional situations overweight and obesity according to the reference test.

\begin{tabular}{|c|c|c|c|}
\hline \multirow{3}{*}{$\begin{array}{l}\text { WAIST/HEIGHT } \\
\text { INDEX } \\
\text { (in units) }\end{array}$} & \multirow{2}{*}{\multicolumn{2}{|c|}{$\begin{array}{l}\text { Reference test or Gold Standard: Lorentz Equation } \\
\text { Overweight and obesity }\end{array}$}} & \multirow[b]{3}{*}{ Totals } \\
\hline & & & \\
\hline & Present & Absent & \\
\hline Positivity > 0.5 & 160 (52 ๙̊ y 108 우) & $9\left(1 \mathrm{\delta}^{\lambda} \mathrm{y} 8\right.$ 우 $)$ & 169 (53 ڤ̂ y 116 우) \\
\hline Negativity $\leq 0.5$ & 11 (4 스 y 7 우) & $120\left(105 \delta^{\lambda}\right.$ y 15 우 $)$ & 131 (109 $\delta^{\lambda}$ y 22 ㅇ) \\
\hline Totals & 171 (56 วิ y 115 우) & $129(106$ गे y 23 우 & $300(162$ के y 138 우) \\
\hline
\end{tabular}

$\hat{\delta}=$ Male gender; and $q=$ Female gender .

SOURCE. Own elaboration

- $\quad$ Sensitivity $=\mathrm{A} / \mathrm{A}+\mathrm{C}=(160 / 171)=0.9357=93.57 \%$

- $\quad$ Specificity $=\mathrm{D} / \mathrm{B}+\mathrm{D}=(120 / 129)=0.9302=93.02 \%$

- Security $=\mathrm{A}+\mathrm{D} / \mathrm{N}=(160+120) /(300)=(280) /(300)=0.9333=93.33 \%$

- $\quad$ Positive likelihood ratio $=$ Sensitivity $/ 1-$ Specificity $=0.9357 / 1-0.9302=0.9357 / 0.0698=13.41=$ Sufficient prognostic efficiency

- Estimation interval at the $95 \%$ confidence level for the positive likelihood ratio $=7.13 \rightarrow 25.00$

- $\quad$ Negative likelihood ratio $=1-$ Sensitivity $/$ Specificity $=1-0.9357 / 0.9302=0.0643 / 0.9302=0.07=$

\section{Sufficient prognostic efficiency}

- $\quad$ Estimation interval at the $95 \%$ confidence level for the negative likelihood ratio $=0.04 \rightarrow 0.072$

Figure 2 shows the prior probability or prevalence (left column), positive and negative likelihood ratios (center column), and posterior probabilities (right column). The prior probability or prevalence, the positive and negative likelihood ratios and the corresponding posterior probabilities corresponded, respectively, to $57.00 \%, 13.41,0.07,95.00 \%$ and $8.00 \%$. 
Figure 2. Absolute frequencies of the 300 patients due to positivity (Waist/Height Index $>0.5$ units) and negativity (Waist/Height Index $\leq 0.5$ units) according to the Waist/Height Index diagnostic test (in units) and due to pathological nutritional situations overweight and obesity according to the reference test.

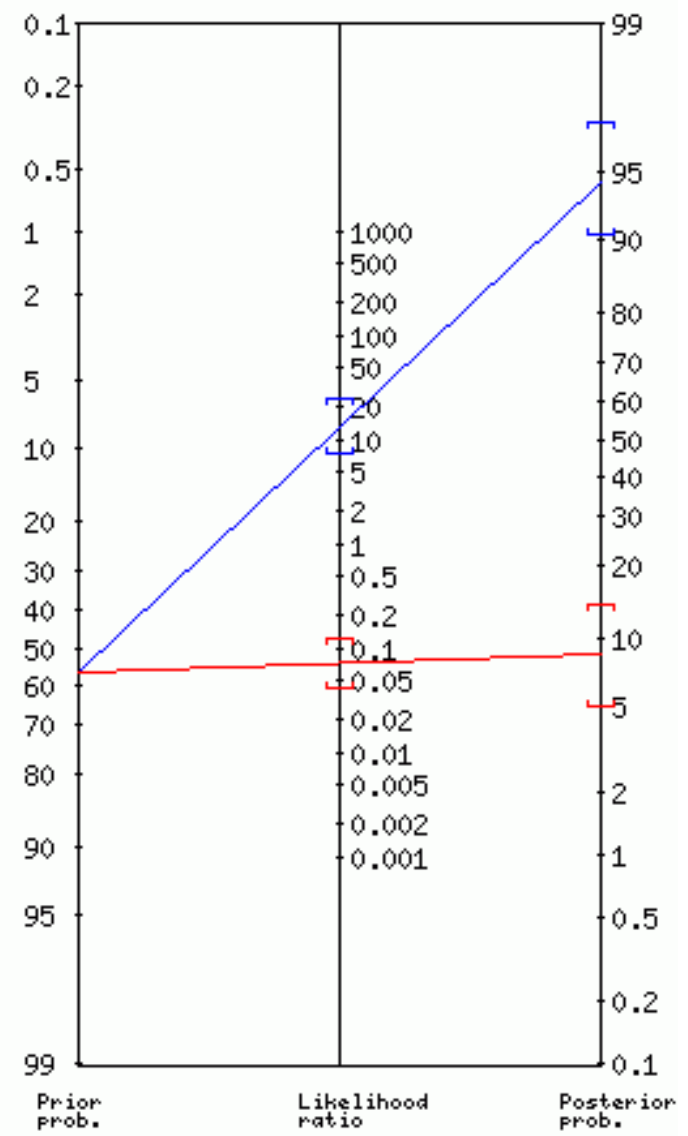

\section{INTERPRETATION OF THE FAGAN NOMOGRAM}

Prevalence or prior probability $=57.00 \%$

\section{POSITIVE TEST:}

\section{Positive likelihood ratio $=\mathbf{1 3 . 4 1}$}

\section{Posterior probability $=\mathbf{9 5 . 0 0 \%}$}

Approximately 1 patient out of 1.1 with a positive test is ill, that is, $100(90.91 \%)$ patients out of 110 with a positive test are ill.

\section{NEGATIVE TEST:}

\section{Negative likelihood ratio $=\mathbf{0 . 0 7}$}

\section{Posterior probability $=\mathbf{8 . 0 0 \%}$}

Approximately 1 patient out of 1.1 with a negative test is healthy, that is, $100(90.91 \%)$ patients out of 110 with a negative test are healthy. 
Table 3 shows the absolute frequencies of the 300 patients by positivity (Waist/Hip Index $\geq 1.01$ units and $\geq 0.81$ units in the male and female genders, respectively) and by negativity (Waist/Hip Index $\leq 1.00$ units and $\leq 0.80$ units in the male and female genders, respectively). according to the Waist/Hip Index diagnostic test and due to pathological nutritional situations overweight and obesity according to the reference test.

Table 3. Absolute frequencies of the 300 patients by positivity (Waist/Hip Index $\geq 1.01$ units in the male gender and $\geq 0.81$ units in the female gender) and by negativity (Waist/Hip Index $\leq 1.00$ units in the male gender and $\leq 0.80$ units in the female gender) according to the Waist/Hip Index diagnostic test (in units) and due to pathological nutritional situations overweight and obesity according to the reference test.

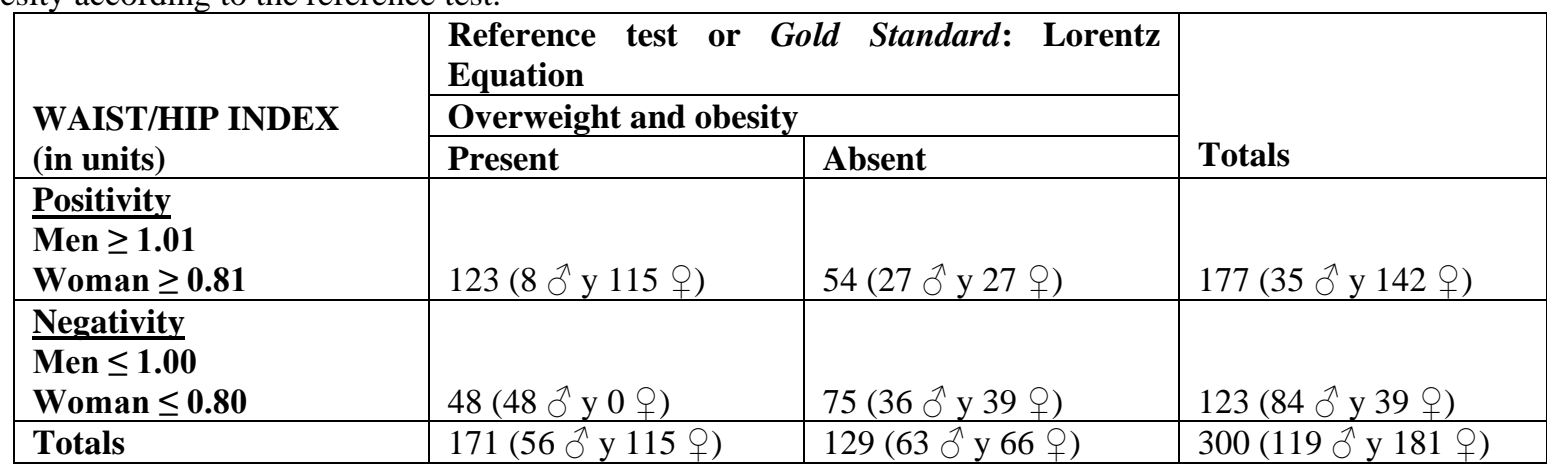

$\widehat{\partial}=$ Male gender; and $q=$ Female gender .

SOURCE. Own elaboration

- $\quad$ Sensitivity $=\mathrm{A} / \mathrm{A}+\mathrm{C}=(123 / 171)=0.7193=71.93 \%$

- $\quad$ Specificity $=\mathrm{D} / \mathrm{B}+\mathrm{D}=(75 / 129)=0.48814=58.14 \%$

- Security $=\mathrm{A}+\mathrm{D} / \mathrm{N}=(123+75) /(300)=(198) /(300)=0.6600=66.00 \%$

- $\quad$ Positive likelihood ratio $=$ Sensitivity $/ 1-$ Specificity $=0.7193 / 1-0.48814=0.7193 / 0.4186=1.72=$

\section{Negligible prognostic efficiency}

- $\quad$ Estimation interval at the $95 \%$ confidence level for the positive likelihood ratio $=1.4 \rightarrow 2.2$

- Negative likelihood ratio $=1-$ Sensitivity/Specificity $=1-0.7193 / 0.48814=0.2807 / 0.48814=0.48=$

\section{Poor prognostic efficiency}

- $\quad$ Estimation interval at the $95 \%$ confidence level for the negative likelihood ratio $=0.4 \rightarrow 0.6$ 
Figure 3. Absolute frequencies of the 300 patients by positivity (Waist/Hip Index $\geq 1.01$ units in the male gender and $\geq 0.81$ units in the female gender) and by negativity (Waist/Hip Index $\leq 1.00$ units in the male gender and $\leq 0.80$ units in the female gender) according to the Waist/Hip Index diagnostic test (in units) and due to pathological nutritional situations overweight and obesity according to the reference test.

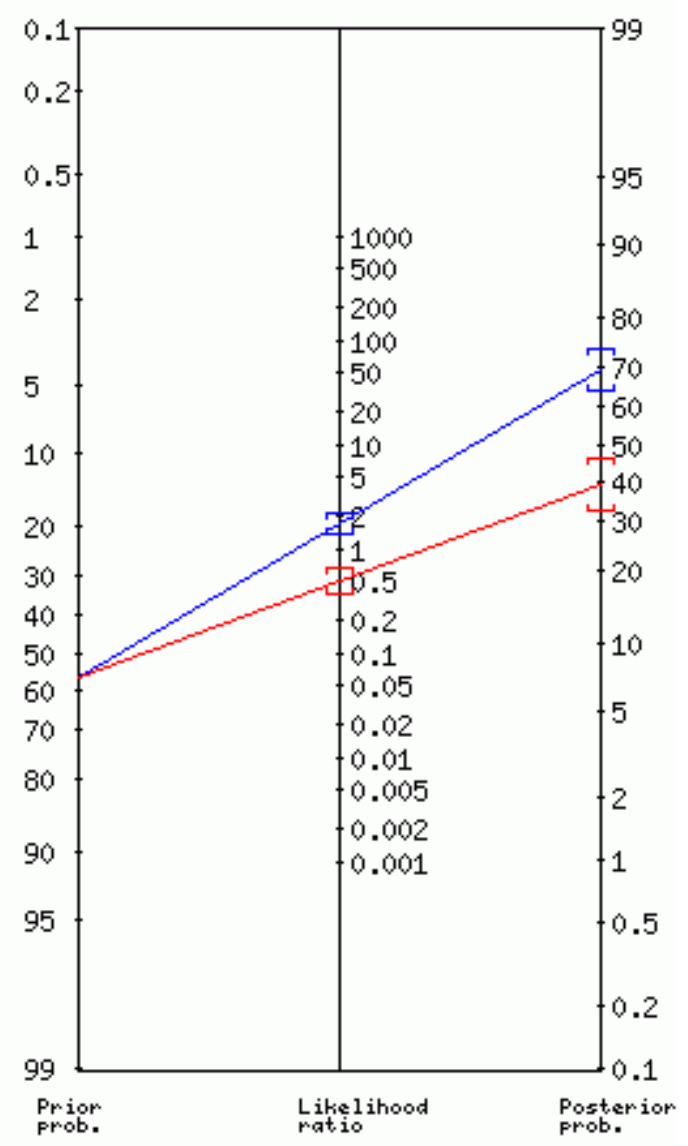

\section{INTERPRETATION OF THE FAGAN NOMOGRAM}

Prevalence or prior probability $=\mathbf{5 7 . 0 0 \%}$

\section{POSITIVE TEST:}

\section{Positive likelihood ratio $=\mathbf{1 . 7 2}$}

Posterior probability $\mathbf{7 0 . 0 0 \%}$

Approximately 1 out of every 1.4 patients with a positive test is sick, that is, $100(71.43 \%)$ of every 140 patients with a positive test is sick

\section{NEGATIVE TEST:}

Negative likelihood ratio $=0.38$

\section{Posterior probability $=\mathbf{3 3 . 0 0 \%}$}

Approximately 1 patient out of every 1.6 with a negative test is healthy, that is, $100(62.50 \%)$ patients out of every 160 with a positive test are healthy. 
The sensitivities, specificities, $\mathrm{RV}(+), \mathrm{RV}(-), \mathrm{CI} 95 \%$ for $\mathrm{RV}(+)$ and $\mathrm{RV}(-)$ and diagnostic capabilities according to Waist/Height Index and Waist/Hip Index diagnostic tests are presented in Table 4.

Table 4. Sensitivities, specificities, positive and negative likelihood ratios and diagnostic capabilities according to Waist/Height Index and Waist/Hip Index diagnostic tests.

\begin{tabular}{|l|l|l|l|l|l|l|}
\hline $\begin{array}{l}\text { Pruebas } \\
\text { diagnósticas }\end{array}$ & Sensibilidades & Especificidades & $\begin{array}{l}\text { Razones de } \\
\text { verosimilitud } \\
\text { positiva }\end{array}$ & $\begin{array}{l}\text { Capacidades } \\
\text { diagnósticas }\end{array}$ & $\begin{array}{l}\text { Razones de } \\
\text { verosimilitud } \\
\text { negativa }\end{array}$ & $\begin{array}{l}\text { Capacidades } \\
\text { diagnósticas }\end{array}$ \\
\hline $\begin{array}{l}\text { Índice } \\
\text { Cintura/Estatura } \\
\text { (en unidades) }\end{array}$ & 0.9357 & 0.9302 & 13.41 & Suficiente & 0.07 & Suficiente \\
\hline $\begin{array}{l}\text { Índice } \\
\text { Cintura/Cadera } \\
\text { (en unidades) }\end{array}$ & 0.7193 & 0.4881 & 1.72 & Insignificante & 0.48 & Escasa \\
\hline
\end{tabular}

SOURCE. Own elaboration

\section{DISCUSSION}

Our results are consistent with the results observed by other authors ${ }^{(3-4,17-20)}$.

The results observed indicate that the Waist/Height Index is the diagnostic test that has the greatest capacity to correctly identify those who do suffer from the disease (Sensitivity) (93.57\%); the greater ability to correctly identify those who do not have the disease (Specificity) (93.02\%); and the highest percentage of true positives and negatives with respect to the total number of patients studied (Security) $(93.33 \%)$.

The $\mathrm{RV}(+)$ and $\mathrm{RV}(-)$ tests were performed to determine whether the tests have sufficient prognostic efficiency or moderate prognostic efficiency when combining sensitivity and specificity in a single expression.

The result observed for the RV(+) test was 13.41 for the Waist/Height Index, which indicates sufficient prognostic efficiency; however, the result observed for the $R V(+)$ test was 1.72 for the Waist/Hip Index, which indicates negligible prognostic efficiency.

The result observed for the $\mathrm{RV}(-)$ test was 0.07 for the Waist/Height Index, which indicates sufficient prognostic efficiency. However, the result observed for the $\mathrm{RV}(-)$ test was 0.48 for the Waist/Hip Index, which indicates poor prognostic efficiency (see Tables 3 and 4).

Finally, the use of $\mathrm{RV}(+)$ and $\mathrm{RV}(-)$ is recommended to jointly evaluate the $\mathrm{S}$ and $\mathrm{E}$ of any diagnostic test, which is generally not done.

\section{CONCLUSIONS}

Con base en el objetivo del presente estudio se concluye que el Waist/Height Index tiene eficiencias pronósticas suficientes cuando se combinaron la sensibilidad y la especificidad en una sola 
expresión mediante la $\mathrm{RV}(+)$ y la $\mathrm{RV}(-)$ : $\mathrm{RV}(+)=13.41$; $\mathrm{RV}(-)=0.07$. Por otra parte, siempre con base en el objetivo del presente estudio, se concluye que el Waist/Hip Index tiene, respectivamente, eficiencias pronósticas insignificante y escasa cuando se combinaron la sensibilidad y la especificidad en una sola expresión mediante la $\mathrm{RV}(+)$ y la $\mathrm{RV}(-)$ : $\mathrm{RV}(+)=1.63 ; \mathrm{RV}(-)=0.38$.

Con respecto a la formulación de hipótesis se rechaza la hipótesis nula $\left(\mathrm{H}_{0}\right)$ y se acepta la hipótesis alterna $\left(\mathrm{H}_{1}\right)$, es decir, hay evidencia estadísticamente significativa al nivel de significancia $(\alpha)$ del $5 \%$ para concluir que la sensibilidad, la especificidad y la seguridad del Waist/Height Index son diferentes de la sensibilidad, la especificidad y la seguridad del Waist/Hip Index: $\mathrm{x}^{2} \mathrm{P}(\alpha=0.0500 ; \mathrm{gl}=1) \geq 3.8416 ; p \leq$ 0.0500. Asimismo, se rechaza la hipótesis nula $\left(\mathrm{H}_{0}\right)$ y se acepta la hipótesis alterna $\left(\mathrm{H}_{1}\right)$, es decir, la $\mathrm{RV}(+)$ y la RV(-) son diferentes según Molinero 2002; Loong 2003; y el Centre for Evidence-Based Medicine 2009.

Finalmente, con respecto a los resultados observados utilizando el Nomograma de Fagan, el Waist/Height Index puede etiquetar aproximadamente a $100(90.91 \%)$ pacientes de cada 110 con prueba positiva como enfermos y también aproximadamente a $100(90.91 \%)$ pacientes de cada 110 con prueba negativa como sanos, mientras que el Waist/Hip Index tan solo puede etiquetar aproximadamente a 100 (71.43\%) pacientes de cada 140 con prueba positiva como enfermos y también aproximadamente a 100 (62.50\%) pacientes de cada 160 con prueba positiva como sanos. En consecuencia, se concluye que el Waist/Height Index es, como prueba diagnóstica, más eficaz que el Waist/Hip Index.

\section{ACKNOWLEDGEMENTS}

The authors thank the Universidad Intercultural Maya de Quintana Roo and the Regional Hospital "Jose Maria Morelos" for having provided the facilities to carry out this work. 


\section{REFERENCES}

1. Saderi N, Escobar C, Salgado-Delgado R. 2013. La alteración de los ritmos biológicos causa enfermedades metabólicas y obesidad. Rev Neurol. (57): 71-78.

2. $\quad$ https://on-enfermeria.com/temario-enfermeria-formula-lorentz/

3. Koch E, Romero T, Manríquez L, Taylor A, Román C, Paredes M, et al. 2008. Razón cinturaestatura: un mejor predictor antropométrico de riesgo cardiovascular y mortalidad en adultos chilenos. Nomograma diagnóstico utilizado en el Proyecto San Francisco. Rev Chil Cardiol. 27(1): 23-35.

4. Huaman J, Alvarez M, Gamboa L, Marino F. 2017. Índice cintura-estatura como prueba diagnóstica del síndrome metabólico en adultos de Trujillo. Rev Med Hered. 28(1): 13-20.

5. Aznar-Orovala E, Mancheño-Alvarob A, García-Lozanoa T, Sánchez-Yepesa M. 2013. Likelihood ratio and Fagan's nomogram: two basic tools for the rational use of clinical laboratory tests. Rev Calid Asist, 28(6): 390-393.

6. Hernández-Sampieri R, Fernández-Collado C, Baptista-Lucio P. 2006. Metodología de la Investigación. México, D.F: McGraw-Hill/Interamericana Editores, S.A. de C.V.

7. Hernández-Ávila M. 2007. Epidemiología. Diseño y Análisis de Estudios. México, D.F.: Editorial Médica Panamericana.

8. INEGI. 2015. Principales resultados de la Encuesta Intercensal 2015 Quintana Roo. Quintana Roo.

9. Donis JH. 2012. Evaluación de la validez y confiabilidad de una prueba diagnóstica. Avances en Biomedicina. 1(2): 73-81.

10. Ruiz-Morales A, Morrillo-Zarate L. 2004. Epidemiología Clínica Investigación Aplicada. Colombia: Editorial Médica Panamericana.

11. Grimes DA, Schulz KF. 2005. Refining clinical diagnosis with likelihood ratios. Lancet. 365(9469): 1500-1505.

12. Gordis L. 2004. Epidemiology. Philadelphia: Elsevier Saunders.

13. Isomaa B, Almgren P, Tuomi T, Forsén B, Lahti K, Nissén M, et al. 2001. Cardiovascular morbidity and mortality associated with the metabolic syndrome. Diabetes Care. 24(4): 683-689.

14. Grundy SM. 2008. Metabolic syndrome pandemic. Arterioscler Trhromb Vasc Biol. 28(4): 629636.

15. WHO Expert Consultation. 2004. Appropriate body-mass index for Asian populations and its implications for policy and intervention strategies. Lancet. 363(9403): 157-163.

16. Cochran WG. 1954. Some methods for strengthening the common $\mathrm{x}^{2}$ tests. Biometrics. 10(4): 417-451. 
17. Harper R, Reeves B. 1999. Reporting of precision of estimates for diagnostic accuracy: a review. BMJ. 318(7194): 1322-1323.

18. Molinero LM. 2002. Valoración de pruebas diagnósticas. Asociación de la Sociedad Española de Hipertensión. 1-7.

19. Loong TW. 2003. Understanding sensitivity and specificity with the right side of the brain. BMJ. 327(7417): 716-719.

20. The Centre for Evidence-Based Medicine develops, promotes and disseminates better evidence for healthcare. (CEBM). 2009. Likelihood Ratios. 1-3. 